\title{
GC/EI-MS method for the determination of phytosterols in vegetable oils
}

\author{
Sarah Schlag ${ }^{1} \cdot$ Yining Huang ${ }^{1} \cdot$ Walter Vetter $^{1}$ (i)
}

Received: 22 July 2021 / Revised: 28 September 2021 / Accepted: 11 October 2021 / Published online: 30 October 2021

(C) The Author(s) 2021, corrected publication 2022

\begin{abstract}
Sterols are a highly complex group of lipophilic compounds present in the unsaponifiable matter of virtually all living organisms. In this study, we developed a novel gas chromatography with mass spectrometry selected ion monitoring (GC/ MS-SIM) method for the comprehensive analysis of sterols after saponification and silylation. A new referencing system was introduced by means of a series of saturated fatty acid pyrrolidides (FAPs) as internal standards. Linked with retention time locking (RTL), the resulting FAP retention indices $\left(\mathrm{RI}_{\mathrm{FAP}}\right.$ ) of the sterols could be determined with high precision. The GC/MS-SIM method was based on the parallel measurement of 17 SIM ions in four time windows. This set included eight molecular ions and seven diagnostic fragment ions of silylated sterols as well as two abundant ions of FAPs. Altogether, twenty molecular ions of $\mathrm{C}_{27^{-}}$to $\mathrm{C}_{31^{-}}$-sterols with 0-3 double bonds were included in the final method. Screening of four common vegetable oils (sunflower oil, hemp oil, rapeseed oil, and corn oil) enabled the detection of 30 different sterols and triterpenes most of which could be identified.
\end{abstract}

Keywords Vegetable oil · Phytosterol · Triterpenol $\cdot$ Sterol composition · Gas chromatography with mass spectrometry $(\mathrm{GC} / \mathrm{MS}) \cdot$ Fatty acid pyrrolidide

\section{Introduction}

Phytosterols make up a substantial part of the unsaponifiable matter of vegetable oils and fats [1]. These bioactive compounds are considered healthy components of our diet [2]. The only known possible adverse effect has been observed in people suffering from phytosterolaemia which is a very rare inherited lipid storage disease [3]. The most relevant positive effect is reduction of the uptake of cholesterol in humans and thus lower serum cholesterol levels. Specifically, daily doses of 1-2 g of 4,4-desmethylsterols or stanols may reduce the serum cholesterol level by about $10 \%[4,5]$. Since very high phytosterol levels may reduce the blood level of $\beta$-carotene, this health claim was limited to a maximum intake of $3 \mathrm{~g} /$ day phytosterols [6]. Further proposed beneficial health benefits of phytosterols are antioxidative and anti-inflammatory effects as well as anticarcinogenic properties [7]. The average daily consumption of

Walter Vetter

walter.vetter@uni-hohenheim.de

Institute of Food Chemistry (170B), University of Hohenheim, Garbenstraße 28, 70599 Stuttgart, Germany $\beta$-sitosterol was shown to be sufficient for an improvement of the clinical symptoms of benign prostate hyperplasia [7, 8]. 4,4-Dimethylsterols (e.g., cycloartenol) and pentacyclic amyrins are currently part of investigations, as they also show beneficial health effects, but by now, they were only tested in medical doses [9].

Chemically, sterols belong to the family of triterpene alcohols and are characterized by a 1,2-cyclophenanthrene backbone which is generally substituted with both a hydroxyl group on C-3 and a branched alkyl chain on C-17. The ring system (and the alkyl chain) of sterols can either be saturated (subgroup of stanols) or carry one or more double bonds (DBs), i.e., the subgroup also named sterols. DBs are often present at C-5 (designated as $\Delta 5$-sterol) and/or C-7 (designated as $\Delta 7$ - or $\Delta 5,7$-sterol) (Fig. 1ii). In addition, the branched alkyl chain can also feature one or, scarcely, two DBs at different positions and may vary in substitution pattern and stereochemistry (Fig. 1iv) [10, 11]. Sterols can further be classified according to the degree of substitution at C-4, i.e., 4-desmethylsterols; 4-methylsterols; and 4,4-dimethylsterols, respectively (Fig. 1i). 4,4-Dimethyl- and 4-methylsterols serve as precursors of 4-desmethylsterols in sterol biosynthesis and typically represent only a small 
amount of the total sterol content of food, but exceptions are known (e.g., tomato seed oil, 40\%) [10, 12]. Other triterpene alcohols such as the pentacyclic amyrins and lupeol (Fig. 1iii), which are often determined together with sterols, are found as well in food [13-15].

Altogether, more than 250 structural variants were described in the scientific literature, but only $\sim 15$ or less sterols are currently determined in routine analysis of vegetable oils [16]. This is mainly due to (i) the wide concentration range of individual sterols, (ii) the lack of reference standards, and the last but not least (iii) insufficiently sensitive and specific analysis methods. After enrichment of the non-saponifiable matter, sterols are mostly analyzed after silylation by means of gas chromatography with flame ionization detection (GC/FID) or mass spectrometry (GC/ MS) [17-19]. The resulting gas chromatograms of sample extracts frequently feature peaks which cannot be assigned and thus remain unlabeled. In this way, however, valuable basic information is lost.

To overcome these problems, we aimed to develop a referencing system according to the concept of retention indices, which was initially introduced by Kováts for isothermal determination using logarithmic retention times [20] and was later adapted by van den Dool and Kratz [21] for the usage of a linear temperature-programmed method. Previous experience with fatty acid pyrrolidides (FAPs) used for structural analysis of fatty acids $[22,23]$ indicated that a group of homologues shares the retention time range of silylated sterols. Moreover, the concept was combined with the retention time locking (RTL) technique [24] and expanded by developing a GC/MS method operated in the selected ion monitoring (SIM) mode for the thorough analysis of silylated sterols. The method was applied to and tested with four typical edible oils.

\section{Materials and methods}

\section{Samples}

Four vegetable oils (sunflower oil, corn oil, hemp oil, and rapeseed oil) were randomly purchased at local supermarkets. They were stored at $4{ }^{\circ} \mathrm{C}$ in the absence of light until sample preparation.

\section{Chemicals and standards}

Nitrogen (99.95\% purity) and helium (99.999\% purity) were from Westfalen Company (Münster, Germany). Ethanol (technical grade, distilled prior to use) was from BASF (Ludwigshafen, Germany), $n$-hexane (HPLC grade) was from Th. Geyer (Renningen, Germany), whereas potassium hydroxide (> $85 \%$ ) and sodium sulfate (>99\%) were from
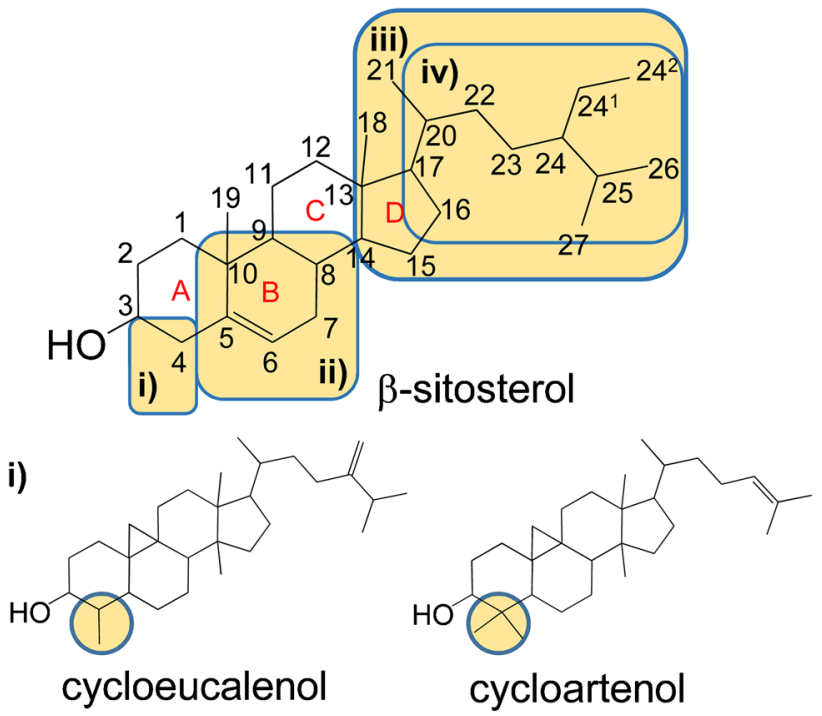

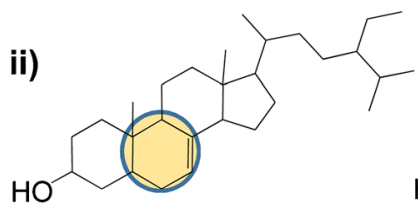
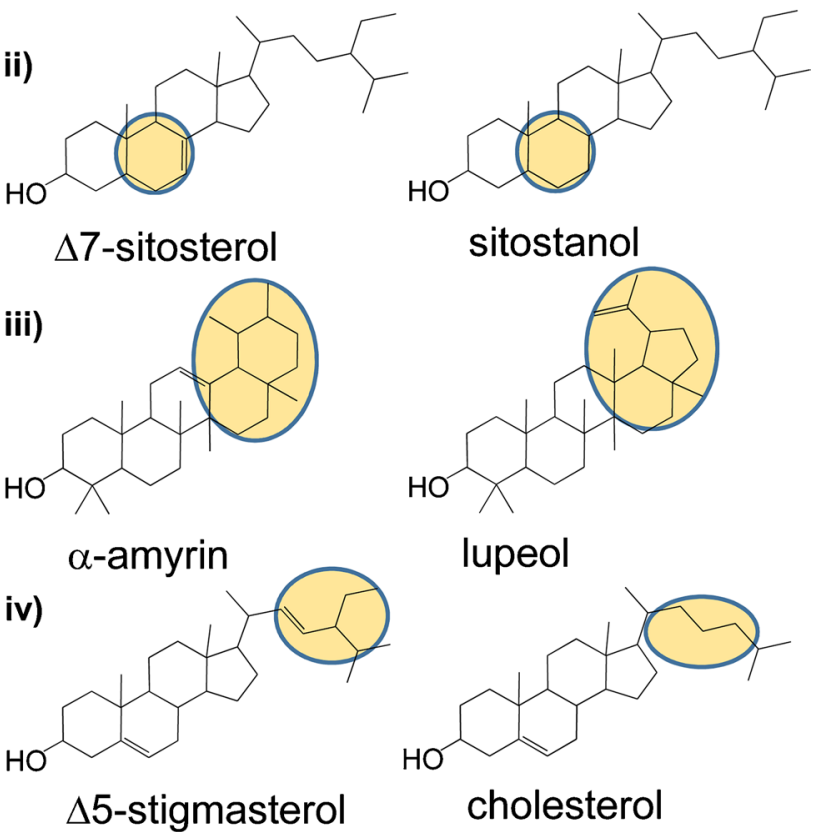

lupeol

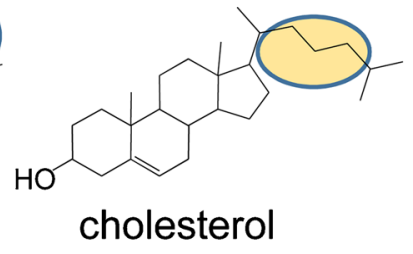

Fig. 1 Structures of important sterols and pentacyclic triterpenes. Sterols can differ in the substitution at C4 (i), in the saturation of the B-ring (ii), and in the substitution of the side chain (iv). Amyrins (iii) have a similar structure

Carl Roth (Karlsruhe, Germany). Stearic acid (18:0; 99\%), lignoceric acid (24:0;>99\%), cerotic acid $(26: 0 ; \geq 90 \%)$, and pyridine were from Sigma-Aldrich (Steinheim, Germany). Pyrrolidine (>98\%), heneicosanoic acid $(21: 0, \geq 98 \%)$, tricosanoic acid $(23: 0, \geq 95 \%)$, and pentacosanoic acid (25:0, $\geq 95 \%$ ) were from TCI (Zwijndrecht, Belgium). Nonadecanoic acid (19:0, $\geq 99 \%)$, arachidic acid (20:0, $\geq 99 \%)$, and behenic acid $(22: 0, \geq 97 \%)$ were from Fluka (Buchs, Switzerland). A semipure $\beta$-sitosterol standard (total sterols, 95\%; unsaturated sterols calculated as $\beta$-sitosterol, $85 \%$ ) was from Merck (Darmstadt, Germany). $5 \alpha$-Cholestane (98\%) 
was from Acros Organics (Geel, Belgium), and the silylating agent consisting of $\mathrm{N}, \mathrm{O}$-bis(trimethylsilyl)-trifluoroacetamide (BSTFA) and trimethylchlorosilane (TMCS), 99:1, v/v (SILYL-991), was from Macherey-Nagel (Düren, Germany).

\section{Preparation of fatty acid pyrrolidides via fatty acid trimethylsilyl esters}

Pyrrolidides were prepared according to Vetter and Walther [23], with slight modifications. About $10 \mathrm{mg}$ of a saturated fatty acid (i.e., 18:0, 19:0, 20:0, 21:0, 22:0, 23:0, 24.0, 25:0, and 26:0) was accurately weighed into a 4-mL screw cap vial. After slowly adding $1 \mathrm{~mL}$ of SILYL-991 solution and $1 \mathrm{~mL}$ pyrrolidine, the vials were closed and stored at room temperature for 3 days. Afterwards, the derivatization agent was evaporated under a gentle stream of nitrogen in a heating block kept at $50{ }^{\circ} \mathrm{C}$. The dry residue was dissolved in $4 \mathrm{~mL} n$-hexane. After adding $4 \mathrm{~mL}$ water, the tube was sealed and shaken and the organic phase was transferred into another tube. The procedure was repeated twice, and the organic phase was then dried with sodium sulfate and filtered through a funnel. The solvent was evaporated as described above, and the residue was re-dissolved in $1 \mathrm{~mL}$ $n$-hexane. For the preparation of the internal standard (IS) solution, aliquots of the individual FAP solutions (18:0-P to 26:0-P) and a solution of 5 $\alpha$-cholestane (conc.) were pipetted in one volumetric flask and diluted with $n$-hexane (FAPIS solution). For the GC/MS analysis, the concentrations of the individual FAPs in the FAP-IS solution were adjusted to a point which allowed detecting them in full scan mode by means of the extracted fragment ion $m / z$. 113. This corresponded to approximately $3 \mathrm{ng}(3 \mu \mathrm{g} / \mathrm{mL})$ for $18: 0-\mathrm{P}$ to $25: 0-$ $\mathrm{P}, 10 \mathrm{ng}(10 \mu \mathrm{g} / \mathrm{mL})$ for 26:0-P considering the weight of the synthesis product. Similarly, $5 \alpha$-cholestane was adjusted to $6 \mu \mathrm{g} / \mathrm{mL}$.

\section{Sample saponification}

Saponification was performed according to Hammann and Vetter [25]. In short, vegetable oil ( $20 \mathrm{mg})$ was weighed into a $6-\mathrm{mL}$ test tube and $1.8 \mathrm{~mL}$ of ethanol and $0.2 \mathrm{~mL}$ of $\mathrm{KOH}$ in water $(50 \%, \mathrm{w} / \mathrm{w})$ were added. The tube was sealed and heated for $1 \mathrm{~h}$ to $80^{\circ} \mathrm{C}$. After cooling to room temperature with an ice bath, $0.5 \mathrm{~mL}$ of water was added and the unsaponifiable matter was extracted with $2 \mathrm{~mL}$ of $n$-hexane.

\section{Trimethylsilylation of the unsaponifiable matter}

Since the amount of the extracted unsaponifiable matter was too small to be precisely weighed, the amount was estimated on the premise that the unsaponifiable matter in a vegetable oil contributed $\sim 2 \%$ to the lipid extract. Accordingly,
$50 \mu \mathrm{L}$ aliquots of the solutions of the unsaponifiable matter were pipetted into $1.5-\mathrm{mL}$ screw cap vials equipped with a $200-\mu \mathrm{L}$ insert and the solvent was evaporated to dryness at $40{ }^{\circ} \mathrm{C}$ under a gentle stream of nitrogen. According to Hammann and Vetter [25], SILYL-991 solution $(50 \mu \mathrm{L})$ and distilled pyridine $(25 \mu \mathrm{L})$ were added and the closed vials were heated to $60{ }^{\circ} \mathrm{C}$ for $30 \mathrm{~min}$. Thereafter, the solvent was evaporated as described above and the residue was redissolved in $100 \mu \mathrm{L}$ of the FAP-IS solution. This solution was used for the GC/MS analysis.

\section{Gas chromatography coupled to mass spectrometry}

The GC/MS analysis was performed on a 6890/5973 N GC/ MS system (Hewlett-Packard/Agilent, Waldbronn, Germany). Splitless injections $(1 \mu \mathrm{L})$ were carried out via an MPS 2 autosampler (Gerstel, Mülheim, Germany) onto a $2 \mathrm{~m}, 0.25 \mathrm{~mm}$ i.d. Zebron guard column with deactivated tubing (Phenomenex, Aschaffenburg, Germany). The guard column was linked via a deactivated press fit connector (BGB Analytik, Rheinfelden, Germany) to a $30 \mathrm{~m}, 0.25 \mathrm{~mm}$ i.d. analytical column coated with a $0.25-\mu \mathrm{m}$ film consisting of $95 \%$ methyl polysiloxane and $5 \%$ phenyl polysiloxane (Optima 5 HT, Macherey-Nagel, Düren, Germany). The carrier gas helium (purity $99.999 \%$ ) was used at a flow rate of $1.0 \mathrm{~mL} / \mathrm{min}$. The column oven was programmed as follows: After $1 \mathrm{~min}$ at $55^{\circ} \mathrm{C}$, T was raised at $20{ }^{\circ} \mathrm{C} / \mathrm{min}$ to $255{ }^{\circ} \mathrm{C}$, then at $1.5^{\circ} \mathrm{C} / \mathrm{min}$ to $283^{\circ} \mathrm{C}$, and finally at $15{ }^{\circ} \mathrm{C} /$ min to $300{ }^{\circ} \mathrm{C}$ (hold time, $11 \mathrm{~min}$ ). Injector, transfer line, ion source, and quadrupole temperatures were set at $250^{\circ} \mathrm{C}$, $280{ }^{\circ} \mathrm{C}, 230{ }^{\circ} \mathrm{C}$, and $150{ }^{\circ} \mathrm{C}$, respectively. The full scan mode covered $\mathrm{m} / \mathrm{z} 50-650$ after a solvent delay of $18 \mathrm{~min}$. As a starting point, two different GC/MS-SIM methods were used (Table 1). Sterol identification was based on relative retention time (RRT), molecular ion, and characteristic fragment ions. The corresponding ${ }^{13} \mathrm{C}$ isotope peak $\left([\mathrm{M}-14]^{+}\right)$ of the $[\mathrm{M}-15]^{+}$fragment ions was compared to a known sterol to exclude a possible molecular ion of a co-eluting unknown sterol.

Retention times were locked by means of a five-point calibration. Namely, the FAP-IS solution was measured with the nominal method pressure and with pressures deviating at $-20 \%,-10 \%,+10 \%$, and $+20 \%$ from the nominal method pressure. The retention time of 24:0-P was set at $32.972 \mathrm{~min}$. The method was relocked every second week and after each cleaning step of the instrument.

\section{Calculation of FAP Indices According to the Kováts Approach}

The FAP retention index ( $\left.\mathrm{RI}_{\mathrm{FAP}}\right)$ of silylated sterols was calculated for a temperature-programmed method in relation to the FAPs in the FAP-IS solution [21] (Eq. 1): 
$\mathrm{RI}_{\mathrm{FAP}}=100 \bullet\left[n+\left(\frac{t(\text { silylated sterol })-t(n)}{t(N)-t(n)}\right)\right]$

with " $n$ " and " $N$ " being the number of carbon atoms of the FAP eluting before and after the silylated sterol and " $t$ " being the corresponding retention times. Four digit numbers were assigned, whereof the first two represented the FAP eluting before the silylated sterol and the last two indicating the relative position according to Eq. 1.

\section{Results and discussion}

\section{Synthesis of pyrrolidides of saturated fatty acids}

Adaption and upscaling of the method of Vetter and Walther (see experimental part) resulted in good yields of highly pure FAPs (Fig. 2a) except for the yield of 26:0-P due to its very poor solubility in $n$-hexane. Also, 26:0-P produced a much smaller peak in the GC/MS chromatogram compared to the other FAPs. Synthesized FAPs were not weighed but aliquots were diluted to approximately $50 \mu \mathrm{g} / \mathrm{mL}$ based on the used weight of the fatty acids. Final volumes for combination were then selected to give approximately comparable peak intensities except 26:0-P which generated a smaller peak (Fig. 3).

As anticipated, FAPs eluted in the retention time range of silylated sterols (i.e., between 21:0-P and 25:0-P, Fig. 3). Hence, the GC/MS chromatogram was divided into four sections, whereas conventional IS in sterol analysis like $5 \alpha$-cholestane and betulin eluted either before or after all sterols $[16,26]$. Initial screening of various samples indicated that 18:0-P to 20:0-P and 26:0-P were outside of the elution range of silylated sterols and thus not required in this study. For this reason, 26:0-P was not included in the final FAP-mix used in the following. However, the RRT of 26:0-P was noted for possible consideration in the case of a sterol

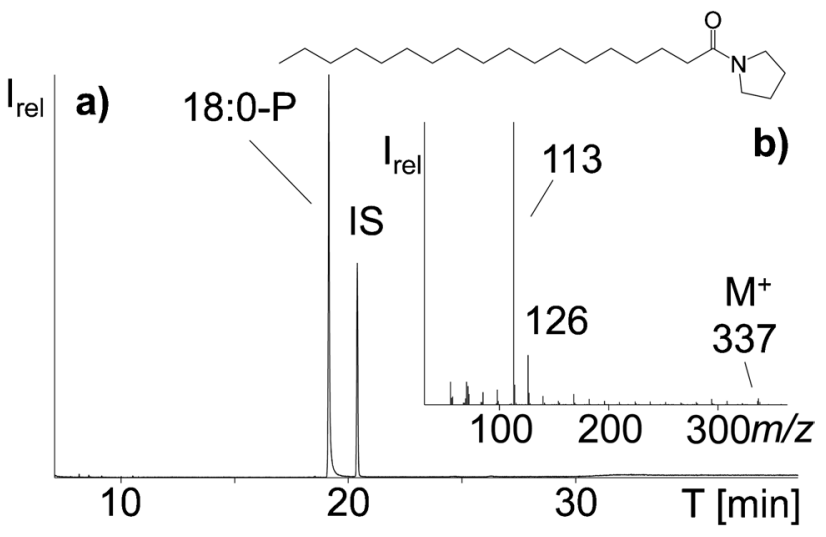

Fig. 2 (a) GC/MS-full scan chromatogram of the synthesized 18:0-P (together with the internal standard (IS, $5 \alpha$-cholestane)) and (b) GC/MS-full scan mass spectrum of 18:0-P

with unexpectedly high retention time. Although 18:0-P to 20:0-P eluted prior to the sterols, these three IS solutions were left in the FAP-mix because they could be interesting in the future for the indexing of more volatile molecules in the silylated unsaponifiable matter eluting in this retention range. Possible examples feature diterpenes and tocochromanols (which eluted between 18:0-P and 23:0-P) as well as the phytosterol precursor squalene (which eluted between 18:0-P and 19:0-P). Compared to the classic use of $n$-alkanes as internal standards, e.g., in the analysis of volatiles [27], FAPs have the decisive advantage that their GC/MS spectra feature only very few abundant fragment ions (Fig. 2b), with distinct predominance of $\mathrm{m} / \mathrm{z} 113$ and $\mathrm{m} / \mathrm{z}$ 126, irrespective of the chain length [28]. This was crucial for the implementation of the GC/MS-SIM mode because all FAPs in the IS mix could be monitored by only these two fragment ions, which are barely present in the GC/MS spectra of silylated sterols.

Table 1 Data of the GC/MS-SIM methods for silylated sterols and triterpene alcohols and the internal fatty acid pyrrolidide (FAP) standards initially used during method development

\begin{tabular}{|c|c|c|c|c|c|c|c|}
\hline & \multirow[t]{2}{*}{ Time window } & \multirow{2}{*}{$\begin{array}{l}\text { Number of } \\
\text { carbon atoms }\end{array}$} & \multicolumn{4}{|c|}{ Molecular ions } & \multirow[t]{2}{*}{ Fragment ions } \\
\hline & & & 0 & 1 & 2 & 3 & \\
\hline \multirow[t]{2}{*}{ SIM 1} & \multirow[t]{2}{*}{$20-41.8 \mathrm{~min}$} & 28 & 474.4 & 472.4 & 470.4 & 468.4 & \multirow{2}{*}{$\begin{array}{l}113.0^{*} ; 126.0^{*} ; \\
129.1 ; 211.2 ; 213.2 ; 215.2 ; 253.2 ; 255.2 ; 296.2\end{array}$} \\
\hline & & 29 & 488.4 & 486.4 & 484.4 & 482.4 & \\
\hline \multirow[t]{6}{*}{ SIM 2} & \multirow[t]{2}{*}{$20-29.6 \mathrm{~min}$} & 27 & 460.4 & 458.4 & 456.4 & 454.4 & \\
\hline & & 30 & 502.5 & 500.4 & 498.4 & 496.4 & \\
\hline & \multirow[t]{2}{*}{$29.6-32.5 \mathrm{~min}$} & 30 & 502.5 & 500.4 & 498.4 & 496.4 & \multirow{2}{*}{$\begin{array}{l}113.0^{*} ; 129.1 ; 189.2 ; 211.2 ; 213.2 ; 215.2 \\
218.3 ; 253.2 ; 255.2 ; 296.2\end{array}$} \\
\hline & & 31 & 516.5 & 514.5 & 512.5 & - & \\
\hline & \multirow[t]{2}{*}{$32.5-41.8 \mathrm{~min}$} & 30 & 502.5 & 500.4 & 498.4 & 496.4 & \multirow{2}{*}{$\begin{array}{l}113.0 * ; 126.0^{*} ; \\
129.1 ; 211.2 ; 213.2 ; 215.2 ; 253.2 ; 255.2 ; 296.2\end{array}$} \\
\hline & & 31 & 516.5 & 514.5 & 512.5 & 510.5 & \\
\hline
\end{tabular}

${ }^{*}$ Fragment ions used for FAPs, all other for silylated sterols and triterpene alcohols 


\section{Stability of the retention indices}

FAP retention indices ( $\left.\mathrm{RI}_{\mathrm{FAP}}\right)$ of silylated sterols in the semipure $\beta$-sitosterol standard (unsaturated sterols calculated as $\beta$-sitosterol $\sim 85 \%$, along with low shares of cholesterol, campesterol, and stigmasterol) were highly reproducible (see Electronic Supplementary Material (ESM) Table S1). Fluctuations in individual measurements were generally within $\Delta \mathrm{RI}_{\mathrm{FAP}}<1$. This allowed us to present retention data of sterols by means of $\mathrm{RI}_{\mathrm{FAP}}$ instead of the commonly used RRT which are known to be less stable [20].

Long-term stability of the $\mathrm{RI}_{\mathrm{FAP}}$ was tested by measuring characteristic (silylated) sterols from four oils at intervals of 6 and 2 weeks (1.5 months in total, ESM Table S2). Resulting fluctuations of three sterols (clerosterol, $\Delta 7$-sitosterol, and cycloartenol) and the triterpene alcohol $\beta$-amyrin were slightly larger ( $>1.5 \mathrm{RI}_{\mathrm{FAP}}$ units) than in the initial standard solution, but never $>2.1 \mathrm{RI}_{\mathrm{FAP}}$ units (ESM Table S2). These four compounds have in common that they co-eluted with another sterol or unknown compounds (valid for clerosterol) in samples. Overall, however, variations were relatively small, and all peaks could be correctly assigned by combining the $\mathrm{RI}_{\mathrm{FAP}}$ value with GC/MS data. Therefore, the impact of matrix effects and co-elutions on the $\mathrm{RI}_{\mathrm{FAP}}$ was considered to be negligible. However, the variations caused the listing of $\mathrm{RI}_{\mathrm{FAP}}$ values by whole numbers and naming the first decimal was omitted.

\section{Implementation of retention time locking}

Long-term measurements (almost 1 year) indicated that $\mathrm{RI}_{\mathrm{FAP}}$ values and separation efficacy slightly changed with the aging of the GC column (ESM Fig. S1 and Fig. S2). Moreover, cutting the GC column as part of routine system

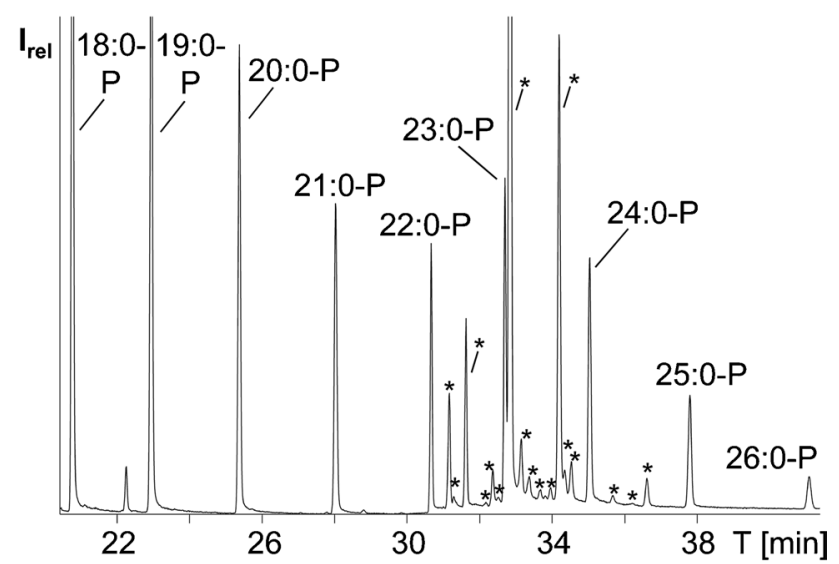

Fig. 3 GC/MS-SIM chromatogram of the silylated unsaponifiable matter of sunflower oil with synthesized fatty acid pyrrolidides (18:0-P to 26:0-P) as internal standard. Sterols are marked with an asterisk maintenance affected the stability of $\mathrm{RI}_{\mathrm{FAP}}$ values. Namely, shortening the GC column by $\sim 1.5 \mathrm{~m}$ not only decreased retention times but also unevenly affected $\mathrm{RI}_{\mathrm{FAP}}$ values (ESM Fig. S1, circled). For instance, $\mathrm{RI}_{\mathrm{FAP}}$ values partly dropped or increased (e.g., in the range of $\Delta 5$-campesterol to $\Delta 7$-campesterol) and later on dropped again (e.g., stigmasterol, ESM Fig. S1c). In order to omit frequent substitution of the column, retention time locking was introduced by locking the retention time of 24:0-P at $32.972 \mathrm{~min}$. Subsequent measurements every 2 weeks with and without retention time locking (RTL) showed that relocking after routine system maintenance was sufficient for high long-term quality of $\mathrm{RI}_{\mathrm{FAP}}$ values. However, strong changes in column length $(>1 \mathrm{~m}$ ) should be omitted in order to exclude that resulting retention time values get outside the calibration range.

All in all, RTL considerably improved the stability of $\mathrm{RI}_{\mathrm{FAP}}$ values of individual silylated sterols compared to the non-locked procedure (Fig. 4, ESM Fig. S3) Stronger deviations were observed when peak tailing occurred with FAP-IS (mid-November and early January) (ESM Fig. S3, circled, and Fig. S4). Subsequent system maintenance (replacing guard column and glass liner) resulted again in correct $\mathrm{RI}_{\mathrm{FAP}}$ values (ESM Fig. S3). Hence, routine measurements of the FAP-IS mix and inspection of peak shapes were introduced for quality control. Overall, the implementation of RTL improved the performance of $\sim 90 \%$ of all sterols.

\section{Selection of suitable GC/MS-SIM ions for silylated sterols}

The most relevant structural information of silylated sterols is provided by the molecular ion. Sterols feature 27-31 C-atoms and $0-3$ DBs, which adds up to $5 \times 4=20$ molecular ions (Table 2). Differentiation of isomers required the additional monitoring of diagnostic fragment ions (and $\mathrm{RI}_{\mathrm{FAP}}$ values). In addition, two characteristic fragment ions for FAPs $(\mathrm{m} / z 113$ and 126) had to be included in the method. Previous investigations showed that 15-18 SIM values can be measured simultaneously without loss of quality [29, 30]. In the present case, 17 SIM ions were selected and still provided a cycle per second rate of $>2$. Hence, time windows were implemented/ required in order to keep information high (Tables 1 and 2).

With regard to fragment ions, the following ones were considered most important for silylated sterols. Stanols show the base peak at $\mathrm{m} / \mathrm{z} 215$, which is formed by loss of the entire side chain along with the three carbons C-15 to $\mathrm{C}-17$ of ring $\mathrm{D}$ and the TMSOH group [31]. $\Delta 5$ - and $\Delta 7$-sterols both feature the diagnostic $\mathrm{m} / \mathrm{z} 213$ and $\mathrm{m} / \mathrm{z}$ 255; the latter results from elimination of the entire side chain on $\mathrm{C}-17$ along with the TMSOH group. Both groups can be distinguished by $m / z, 129$, which is the base peak of $\Delta 5$-sterols (TMSOH group and carbons $\mathrm{C}-1$ to $\mathrm{C}-3$ of ring A, Fig. 1). Moreover, sterols with two DBs in ring B 

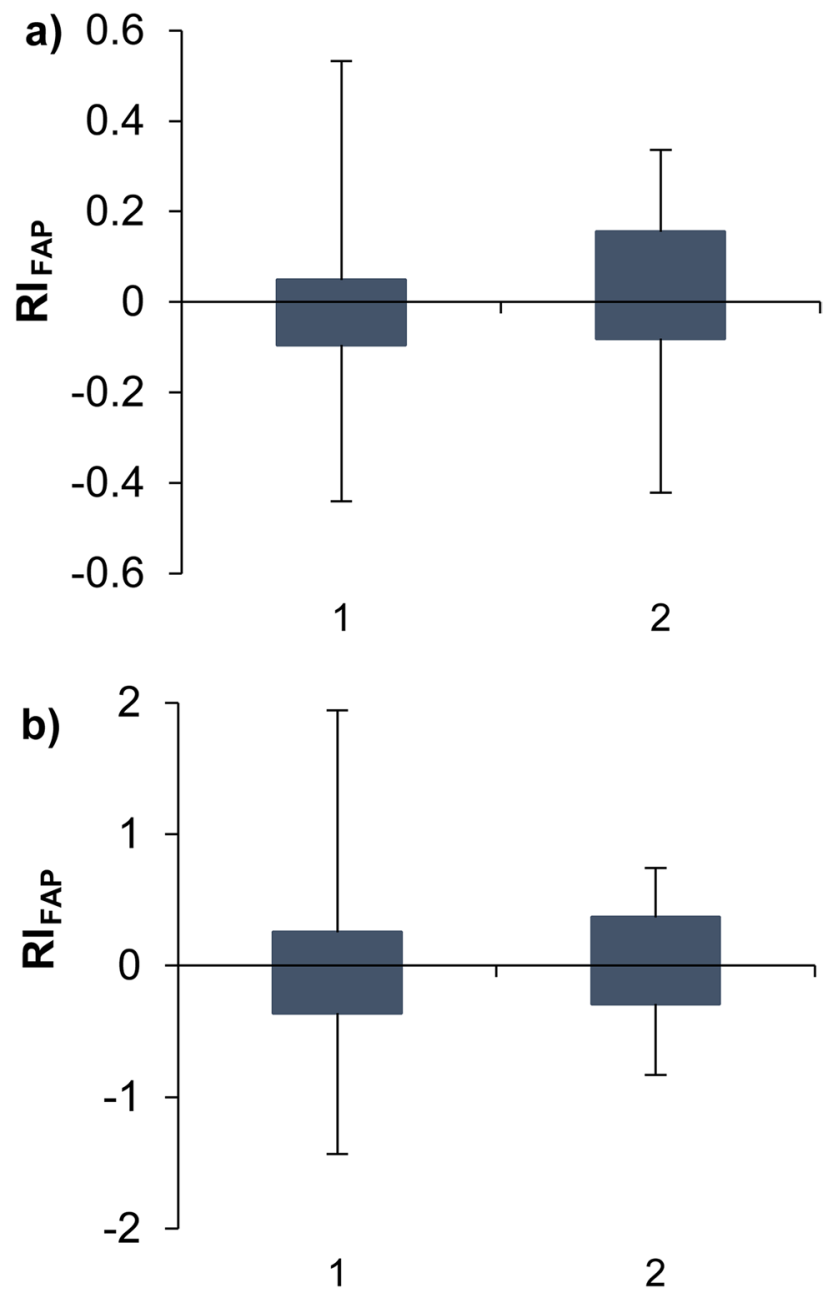

Fig. 4 Box-plots of the shifts in the $\mathrm{RI}_{\mathrm{FAP}}$ determined for silylated (a) cholesterol and stigmasterol (b), determined (1) with a non-locked and (2) with a retention time locked (RTL) GC/MS-SIM method in the course of 5 months. Outliers are excluded

( $\Delta 5,7-/ \Delta 5,8$-sterols) feature the corresponding fragment ions at $m / z 211$ and $m / z$ 253. Lastly, $m / z 296$ ([M-84-TM$\mathrm{SOH}]^{+}$) was included in the method, because it verifies $\Delta 5$-sterols with a second DB on C-24(C-24 $\left.{ }^{1}\right)$ or C-24(C-25).

Finally, two fragment ions $(\mathrm{m} / \mathrm{z} 218$ and $\mathrm{m} / \mathrm{z} 189)$ were selected because they allowed for indicating pentacyclic triterpene alcohols, which are also partly abundant in the unsaponifiable matter of plants and which are commonly listed as 4,4-dimethylsterols [13-15]. GC/MS spectra of pentacyclic triterpene alcohols usually show a weak molecular ion (ESM Fig. S5), but with abundant fragment ions at $m / z 218$ and $m / z, 189$. Both ions are formed by a retroDiels-Alder reaction in ring $C[32,33]$. Moreover, the abundance ratio of both fragment ions allowed distinguishing amyrins and further pentacyclic triterpene alcohols with a DB on C-12 (higher abundance of $m / z 218$ ) from those with a DB on C-13 and lupeol (higher abundance of $\mathrm{m} / z, 189$ ). Further diagnostic fragment ions such as $\mathrm{m} / \mathrm{z}, 343$ for spinasterol [11] may be helpful as well, but were not included in the final method in order to keep track on basic features. However, this and further SIM values [9] may be selectively measured in separate confirmatory GC/MS runs.

Parallel measurement of eight molecular ions allowed for the determination of nine fragment ions and two SIM values for IS in order cover the full array. Hence, time windows had to be implemented. The time windows had to be set very tightly (four time windows within $10 \mathrm{~min}$ ). In order to find appropriate positions without loss of information, each sample was initially analyzed by two independent GC/ MS-SIM runs on the 20 molecular ions. Namely, molecular ions of $\mathrm{C}_{28^{-}}$and $\mathrm{C}_{29}$-sterols were measured in SIM method 1 and those of $\mathrm{C}_{27^{-}}, \mathrm{C}_{30^{-}}$, and $\mathrm{C}_{31^{-}}$-sterols in SIM method 2 (Table 1). An overlap of $\mathrm{C}_{27^{-}}$and $\mathrm{C}_{31}$-sterols could be ruled out, as GC retention times of sterol-TMS are increasing with the number of carbon atoms [34]. Consequently, the molecular ions of $\mathrm{C}_{27}$-sterols were only measured in the first part of the $\mathrm{GC}$ run (here: until $29.6 \mathrm{~min}$ ), and $\mathrm{C}_{31}$-sterols thereafter until the end of the run. Most fragment ions were measured throughout the run, with the exception of pentacyclic triterpene alcohols, because these $\mathrm{C}_{30}$-compounds eluted within (in the middle section) SIM method $2[15,35]$.

\section{GC/MS-SIM analysis of the unsaponifiable matter of four edible oils on silylated sterols}

Thirty sterols and triterpene alcohols were detected in the silylated unsaponifiable matter of four different oils by GC/ MS-SIM (Table 3). Most of them could be verified by GC/

Table 2 Selected molecular and fragment ions of the silylated sterols and triterpene alcohols (mass defect of the isotopes is included)

\begin{tabular}{|c|c|c|c|c|c|c|c|}
\hline & & 27 & 28 & 29 & 30 & & 31 \\
\hline \multirow[t]{5}{*}{ Molecular ion } & 0 & 460.4 & 474.4 & 488.4 & 502.5 & & 516.5 \\
\hline & 1 & 458.4 & 472.4 & 486.4 & 500.4 & & 514.5 \\
\hline & 2 & 456.4 & 470.4 & 484.4 & 498.4 & & 512.5 \\
\hline & 3 & 454.4 & 468.4 & 482.4 & 496.4 & & 510.5 \\
\hline & & Saturated & $\Delta 5$-Sterol & $\Delta 7$-Sterol & $\Delta 5,7$ - or $\Delta 5,8$-sterols & $\Delta 24-$ Sterols & Amyrins \\
\hline Fragment ion & & 215.2 & $129.1,213.2,255.2$ & $255.2,213.2$ & $253.2,211.2$ & 296.2 & $189.2,218.3$ \\
\hline
\end{tabular}


MS in full scan mode, but some low abundant sterols could only be detected via GC/MS-SIM. Sterols were detected with 27-31 C-atoms and 0-2 DBs in different $\Delta$-positions. The highest structural diversity was observed in the group of $\mathrm{C}_{29}$-sterols $(n=12)$, which included the most prominent sterol, $\beta$-sitosterol. Varieties of $\mathrm{C}_{28^{-}}(n=7)$ and $\mathrm{C}_{30^{-}}$-sterols ( $n=8$, including three triterpene alcohols) were also high while only one $\mathrm{C}_{27}$-sterol (cholesterol, \#1, 1 DB) and two $\mathrm{C}_{31}$-sterols were detected.

The most important mass spectral data (base peak, molecular ion, the number of carbon atoms, and DB equivalents) of the sterols and triterpene alcohols are summarized in Table 3. Since DBs and additional rings (here: cyclopropane rings) are isobaric, DB numbers were only assigned when unequivocally known while sterols with a cyclopropane ring (e.g., 24-methylenecycloartanol) were listed in ${ }^{x} r_{y}$ mode, where $x$ denotes the number of $\mathrm{C}$-atoms of the ring and the $y$ denotes the connection points on the sterol backbone (e.g., ${ }^{3} r_{9,10}$ for 24-methylenecycloartanol, Table 3). Similarly, pentacyclic triterpene alcohols like amyrins were marked with the same ${ }^{x} r_{y}$ system (e.g., ${ }^{6} r_{17,18}$ for $\alpha$-amyrin, Table 3 ).

Detected sterols were categorized by using a 4-level system. Level 1 was assigned to sterols verified by means of an authentic reference standard, whereas level 2 was assigned to major sterols which could be unequivocally verified by GC/MS and literature data. Together, levels 1 and 2 could be assigned to 22 sterols (Table 3). Level 3 was used to specify three sterols which could be tentatively assigned while level 4 was used when abundance was too low to collect structural information (Table 3 ). This is applied to the remaining five sterols. Seven of the level 3 and 4 sterols (all except butyrospermol) and lanosterol (Table 3, *) have not been described in previous studies of these four oils [36-44], because of their low concentration and the additional coelution of lanosterol with $\beta$-sitosterol.

$\mathbf{C}_{28}$-sterols The most relevant representative of this group was campesterol (\#4, 1 DB), which was the second most abundant sterol in all but sunflower oil. Campesterol (\#4) is commonly found in vegetable oils [36, 37, 44]. Rapeseed oil featured brassicasterol (\#2, 2 DBs), which is characteristic for Cruciferae [41]. Other $\mathrm{C}_{28}$-sterols frequently found in edible oils were 24-methylenecholesterol (\#3, 2 DBs) and campestanol (\#6, no DB) [39, 45]. These were detected in all oils except for sunflower oil.

In addition, $\Delta 8$-campesterol (\#7, or its epimer ergost-8enol) was tentatively identified (level 3 ) in rapeseed oil due to the molecular ion at $\mathrm{m} / \mathrm{z} 472\left(\mathrm{C}_{28}\right.$-sterol, $\left.1 \mathrm{DB}\right)$ and its reported elution between $\Delta 5$ - and $\Delta 7$-campesterol $[25,26]$. More details could not be obtained from the GC/MS spectrum because the peak co-eluted with the more abundant stigmasterol ( $\mathrm{C}_{29}$-sterol, $\left.2 \mathrm{DBs}\right)$. Sterol 4 (\#10, $2 \mathrm{DBs}$, level 4) was very low abundant in all samples and it co-eluted with the unknown $\mathrm{C}_{29}$-sterol 3 (\#9, level 4), which was also detected in all four oils.

$\mathrm{C}_{29}$-sterols The twelve $\mathrm{C}_{29}$-sterols featured no $(n=1)$, one $(n=4)$, or two DBs $(n=7)$ (Table 3$)$. $\beta$-Sitosterol (\#14, 1 DB) dominated in all screened oils which is in good accordance with literature data [36, 37, 44]. At slightly higher $\mathrm{RI}_{\mathrm{FAP}}$ value, $\Delta 5$-avenasterol (\#16, $2 \mathrm{DBs}$ ) co-eluted in two oils with sitostanol (\#15, no DB), but could be distinguished by GC/MS-SIM due to both having different molecular ions and fragment ions.

Other common $\mathrm{C}_{29}$-sterols (level 1 or 2) in the samples were stigmasterol (\#8, 2 DBs); clerosterol (\#12, 2 DBs); $\Delta$ 7-avenasterol (\#27, 2 DBs); stigmasta-5,24(25)-dienol (\#20, 2 DBs); and $\Delta 7$-sitosterol (\#23, 1 DB). $\Delta 7$-Sitosterol is the $\Delta 7$-isomer of $\beta$-sitosterol, whereas the other sterols were isomers of $\Delta 5$-avenasterol, with one $\mathrm{DB}$ at $\Delta 5$ - or $\Delta 7$-position and the second one located in the side chain. $\Delta 7$-Avenasterol was detected in all oils except in rapeseed oil, whereas the other four sterols were detected in all samples. Gramisterol (\#22, 2 DBs, level 2), which co-eluted with sterol 7 (\#21, 2 DBs, level 4), particularly stood out, as it was the only detected 4-methylsterol with less than 30 carbon atoms. It was detected in three out of the four analyzed oils and has already been described in sunflower oil and corn oil by Schwartz et al. [36]. $\Delta 8$-sitosterol (\#18, 1 DB, level 3 ) was tentatively identified in hemp oil and sunflower oil analogous to $\Delta 8$-campesterol (see previous section). Indeed, it co-eluted with $\beta$-amyrin (\#17, $2 \mathrm{DBs),} \mathrm{but} \mathrm{due} \mathrm{to} \mathrm{the} \mathrm{dif-}$ ferent fragmentation of amyrins, both compounds could be differentiated by the GC/MS-SIM method.

Unknown sterol 1 (\#5, 2 DBs) was detected in traces in sunflower oil. It eluted between campesterol (\#4, 1 DB) and campestanol (\#6, no DB), with the latter one being absent in sunflower oil. The last detected $\mathrm{C}_{29}$-sterol (sterol 3, \#9, 2 DBs, level 4) was already mentioned in the previous section, as it co-eluted with unknown sterol 4 (\#10, level 4) and thus the fragmentation pattern could not be studied in detail.

$C_{30}$ - and $C_{31}$-sterols All sterols of these two groups were either 4-methyl- or 4,4,-dimethylsterols, or belonged to the pentacyclic triterpene alcohols. Due to the sensitive detection of the latter group by means of $\mathrm{m} / \mathrm{z} 189$ and $\mathrm{m} / \mathrm{z} 218$, $\beta$-amyrin (\#17, $\left.1 \mathrm{DB}, \Delta 12,{ }^{6} r_{17,18}\right)$ could be detected in all samples and $\alpha$-amyrin (\#24, $\left.1 \mathrm{DB}, \Delta 12,{ }^{6} r_{17,18}\right)$ was also detected in three samples.

The third pentacyclic triterpene alcohol, lupeol (\#26, 1 $\left.\mathrm{DB}, \Delta 20,{ }^{5} r_{17,18}\right)$, was difficult to differentiate from the coeluting cycloartenol (\#25, $1 \mathrm{DB},{ }^{3} r_{9,10}$ ) since both GC/MS spectra featured the characteristic fragment ion at $m / z, 189$. Consequently, assignment of lupeol additionally required the presence of $\mathrm{m} / \mathrm{z} 218$ (see above), which was observed in 


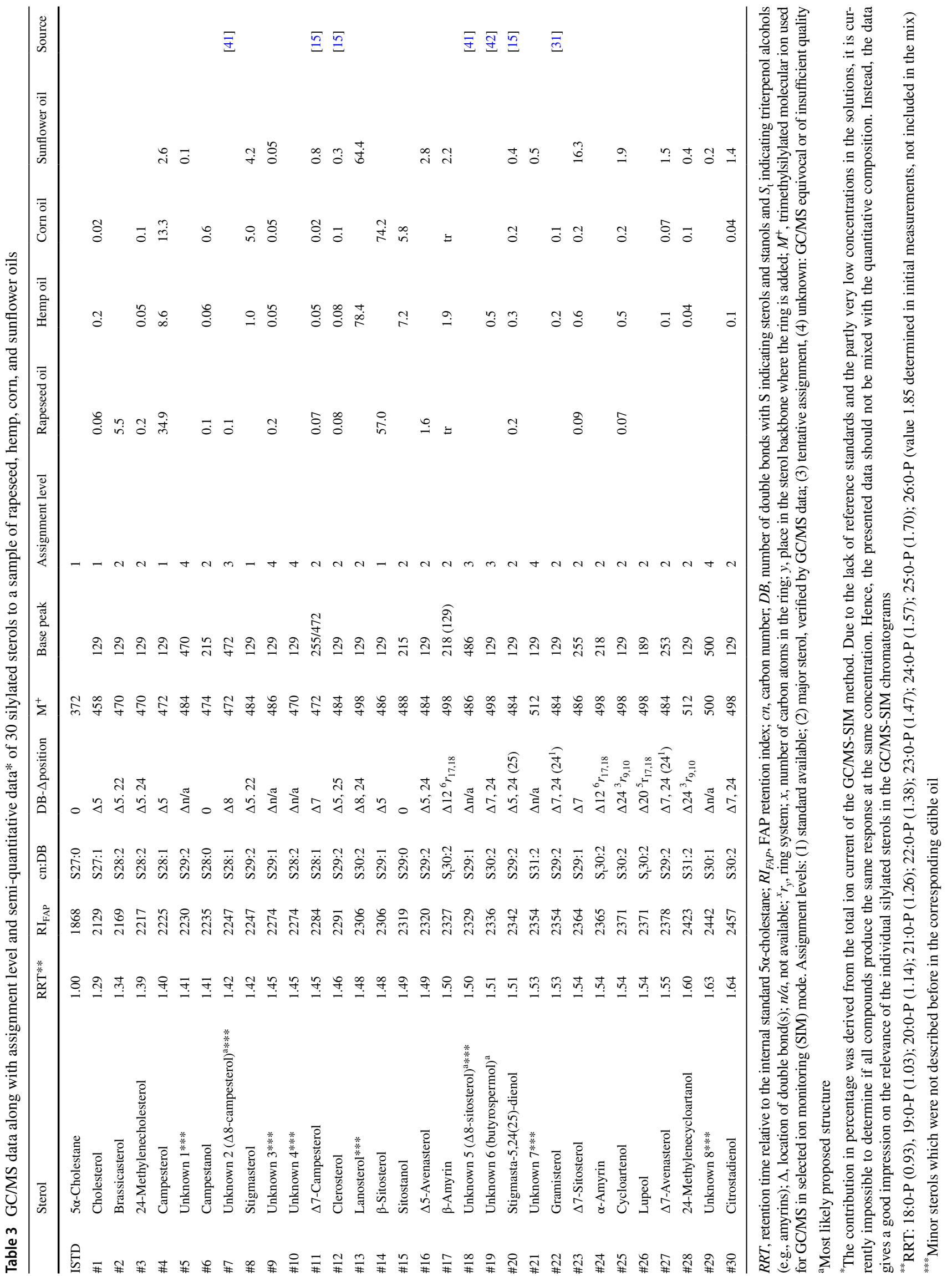




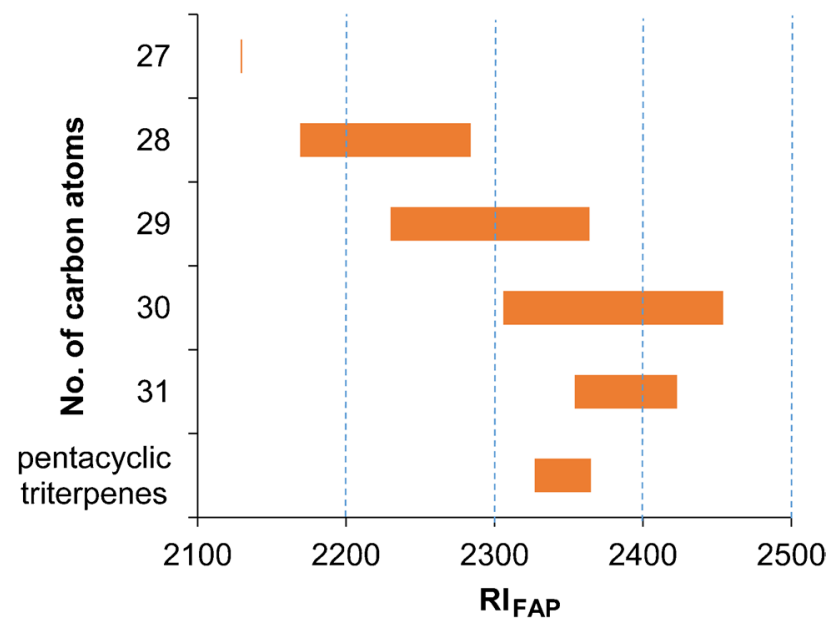

Fig. 5 Retention range $\left(\mathrm{RI}_{\mathrm{FAP}}\right)$ of the 30 silylated sterols and pentacyclic triterpenes grouped after their number of carbon atoms on an Optima 5 HT (30 m, $0.25 \mathrm{~mm}$ i.d., $0.25-\mu \mathrm{m}$ film)

sunflower oil, whereas cycloartenol was detected (fragment ions $m / z, 215$ and $m / z$ 255) in all samples.

24-Methylenecycloartanol ( $\left.\# 28,1 \mathrm{DB},{ }^{3} r_{9,10}\right)$ and citrostadienol (\#30, 1 DB) were found in all oils but rapeseed oil, whereas traces of the 4,4-dimethylsterol lanosterol (\#13, 2 DBs) were detected only in hemp and sunflower oil in larger quantities. Partial co-elution with the dominant $\beta$-sitosterol and comparably low abundant SIM ions hampered the good detection of lanosterol. In the presence of a 14-methyl substituent, diagnostic fragment ions are weakened until completely hindered [31]. The only detectable diagnostic ion for lanosterol apart from the molecular ion was $m / z 215$ (ESM Fig. S6), which was also low abundant in the GC/MS spectrum. As this fragment ion was overlaid by the fragment ions of $\beta$-sitosterol (forms mainly $\mathrm{m} / \mathrm{z} 213$ ), lanosterol could only be identified by its molecular ion. 4-Monomethylsterols like citrostadienol formed the same fragment pattern in $\mathrm{GC} /$ MS-SIM mode (ESM Fig. S6), because diagnostic fragment ions in the ring system are shifted by $14 \mathrm{u}($ e.g., $m / z 213 \rightarrow$ $m / z, 227)$ [31].

Butyrospermol (\#19, 2 DBs, level 3) was tentatively identified in hemp oil by comparison with previously published GC/MS data [38, 43, 46]. Sterol 7 (\#21, level 4) showed the molecular ion at $\mathrm{m} / \mathrm{z} 512$ which indicated the presence of 32 carbon atoms and 2 DBs. Because of its low abundance in sunflower oil and exactly the same $\mathrm{RI}_{\mathrm{FAP}}$ (full co-elution, Table 3) with gramisterol (\#22, $\left.\mathrm{C}_{29}, 2 \mathrm{DBs}\right)$, structural details could not be established. However, the benefits of the GC/MS-SIM methods were apparent because both sterols could be distinguished from each other. Similarly, the unknown sterol 8 ( \#29, 1 DB, level 4) was detected in traces in sunflower oil. It eluted between 24-methylenecycloartanol (\#28) and citrostadienol (\#30) from the GC column.

\section{Establishing of the time windows}

In the last step, the two initial GC/MS-SIM methods were merged by establishing time windows based on the first and last eluting sterol of a given chain length (Fig. 5). Although all groups were overlapping (except for cholesterol, which was the only detected $\mathrm{C}_{27}$-sterol), this could be managed by means of time windows with eight molecular ions each (two chain lengths) with one exception. Namely, the unknown $\mathrm{C}_{31}$-sterol (\#21) eluted before the last $\mathrm{C}_{29}$-sterol (\#27, $\Delta 7$-avenasterol). Hence, the molecular ion of sterol \#21 ( $\mathrm{m} / \mathrm{z}$ 512) was included in time window 3 by substitution of $m / z$ 496.4 because $\mathrm{C}_{30}$-sterols with $3 \mathrm{DBs}$ were not detected at all (Table 4).

Since the time windows had to be set very tightly, RTL played a particular role in order to avoid shifts and thus loss of compounds (Table 4). At this point, it should be noted

Table 4 GC/MS-SIM parameters of the final determination method of silylated sterols in edible oils

\begin{tabular}{|c|c|c|c|c|}
\hline $\begin{array}{l}\text { Time win- } \\
\text { dow }\end{array}$ & $\mathrm{RI}_{\mathrm{FAP}}$ & Retention-independent ions & Group & Retention-dependent ions \\
\hline \multirow[t]{2}{*}{1} & \multirow[t]{2}{*}{$2100-2200$} & \multirow[t]{4}{*}{$113.0 ; 126.0 ; 129.1 ; 211.2 ; 213.2 ; 215.2 ; 253.2 ; 255.2 ; 296.2$} & $\mathrm{C}_{27}$ & $454.4,456.4,458.4,460.4$ \\
\hline & & & $\mathrm{C}_{28}$ & $468.4,470.4,472.4,474.4$ \\
\hline \multirow[t]{2}{*}{2} & \multirow[t]{2}{*}{$2200-2300$} & & $\mathrm{C}_{28}$ & $470.4,472.4,474.4$ \\
\hline & & & $\mathrm{C}_{29}$ & $482.4,484.4,486.4$ \\
\hline \multirow[t]{4}{*}{3} & \multirow[t]{4}{*}{$2300-2400$} & \multirow[t]{4}{*}{$113.0 ; 129.1 ; 211.2 ; 213.2 ; 215.2 ; 253.2 ; 255.2 ; 296.2$} & $\mathrm{C}_{29}$ & $482.4,484.4,486.4,488.4$ \\
\hline & & & $\mathrm{C}_{30}$ & $498.4,500.4$ \\
\hline & & & $\mathrm{C}_{31}$ & 512.5 \\
\hline & & & Amyrins & $189.2,218.3$ \\
\hline \multirow[t]{2}{*}{4} & \multirow[t]{2}{*}{$2400-2500$} & \multirow[t]{2}{*}{$113.0 ; 126.0 ; 129.1 ; 211.2 ; 213.2 ; 215.2 ; 253.2 ; 255.2 ; 296.2$} & $\mathrm{C}_{30}$ & $496.4,498.4,500.4,502.5$ \\
\hline & & & $\mathrm{C}_{31}$ & $510.5,512.5,514.5,516.5$ \\
\hline
\end{tabular}


that the present GC/MS-SIM method was based on 30 sterols. Further oils will likely include other (unknown) sterols [31]. Hence, analysis of additional edible oils may necessitate slight shifts in the time windows. However, the $[\mathrm{M}-14]^{+}$ signals need to be carefully examined as well (see "Materials and methods"). As 14-methylsterols like 24-methylenecycloartanol (\#28, $1 \mathrm{DB},{ }^{3} r_{9,10} \mathrm{M}^{+}$at $m / z$ 512) form a prominent $[\mathrm{M}-15]^{+}$ion $(\mathrm{m} / \mathrm{z} 497)$, the respective ion emerging from the ${ }^{13} \mathrm{C}$ isotope peak (nominally $[\mathrm{M}-14]^{+}$) will be displayed in the corresponding SIM window more intense than $\mathrm{M}^{+}$. The presence of another sterol with one carbon atom less (isobaric with $[\mathrm{M}-14]^{+}$) needs to be excluded by comparison of the relative intensities of these ions. This is easy to be carried out in the case of known sterols but challenging in the case of unknown sterols. Hence, a permanent inspection of the setup is mandatory, especially in the initial phase. Here, it could be advisable to occasionally run the initial two SIM runs (Table 1).

\section{Conclusions}

FAP retention indices were successfully introduced for the analysis of sterols. Implementation of a RTL method improved the precision of $\mathrm{RI}_{\mathrm{FAP}}$ values. The resulting $\mathrm{RI}_{\mathrm{FAP}}$ values proved to be a good alternative to the conventionally used RRT to internal standards like $5 \alpha$-cholestane or betulin. Application of the GC/MS-SIM mode enabled the detection of thirty sterols and triterpene alcohols in only four different edible oils.

Supplementary Information The online version contains supplementary material available at https://doi.org/10.1007/s00216-021-03730-9.

Funding Open Access funding enabled and organized by Projekt DEAL. This project was funded by Deutsche Forschungsgemeinschaft (DFG) via grant no. VE 164/20-1. Initial parts of the research were funded by a $\mathrm{PhD}$ grant to S.S. by Landesgraduiertenförderung Baden-Wuerttemberg.

\section{Declarations}

Conflict of interest The authors declare no competing interests.

Open Access This article is licensed under a Creative Commons Attribution 4.0 International License, which permits use, sharing, adaptation, distribution and reproduction in any medium or format, as long as you give appropriate credit to the original author(s) and the source, provide a link to the Creative Commons licence, and indicate if changes were made. The images or other third party material in this article are included in the article's Creative Commons licence, unless indicated otherwise in a credit line to the material. If material is not included in the article's Creative Commons licence and your intended use is not permitted by statutory regulation or exceeds the permitted use, you will need to obtain permission directly from the copyright holder. To view a copy of this licence, visit http://creativecommons.org/licenses/by/4.0/.

\section{References}

1. Mitei YC, Ngila JC, Yeboah SO, Wessjohann L, Schmidt J. Profiling of phytosterols, tocopherols and tocotrienols in selected seed oils from Botswana by GC-MS and HPLC. J Am Oil Chem Soc. 2009;86:617-25. https://doi.org/10.1007/s11746-009-1384-5.

2. European Commission, Scientific Committee on Food. General view of the scientific committee on food on the long-term effects of the intake of elevated levels of phytosterols from multiple dietary sources, with particular attention to the effects on $\beta$-carotene; 2002.

3. Lütjohann D, von Bergmann Kv. Phytosterolaemla: diagnosis, characterization and therapeutical approaches. Ann Med. 1997;29:181-4. https://doi.org/10.3109/07853899708999333.

4. Normén L, Frohlich J, Trautwein E. Role of plant sterols in cholesterol lowering. Phytosterols as functional food components and nutraceuticals. 2004:243-315.

5. Schröder M, Vetter W. High-speed counter-current chromatographic separation of phytosterols. Anal Bioanal Chem. 2011;400:3615-23. https://doi.org/10.1007/s00216-011-4995-2.

6. EFSA Panel on Dietetic Products, Nutrition and Allergies. Scientific opinion on the substantiation of health claims related to plant sterols and plant stanols and maintenance of normal blood cholesterol concentrations (ID 549, 550, 567, 713, 1234, $1235,1466,1634,1984,2909,3140$ ), and maintenance of normal prostate size and normal urination (ID 714, 1467, 1635) pursuant to Article 13 (1) of Regulation (EC) No 1924/2006. EFSA Journal. 2010;8:1813.

7. Shahzad N, Khan W, Md S, Ali A, Saluja SS, Sharma S, AlAllaf FA, Abduljaleel Z, Ibrahim IAA, Abdel-Wahab AF, Afify MA, Al-Ghamdi SS. Phytosterols as a natural anticancer agent: current status and future perspective. Biomed Pharmacother. 2017;88:786-94. https://doi.org/10.1016/j.biopha.2017.01.068.

8. Ramprasath VR, Awad AB. Role of phytosterols in cancer prevention and treatment. J AOAC Int. 2015;98:735-8. https://doi.org/ 10.5740/jaoacint.SGERamprasath.

9. Zhang T, Xie L, Liu R, Chang M, Zhang H, Jin Q, Wang X. Revisiting the 4,4-dimethylsterols profile from different kinds of vegetable oils by using GC-MS. LWT. 2020;124:109163. https:// doi.org/10.1016/j.1wt.2020.109163

10. Piironen V, Lindsay DG, Miettinen TA, Toivo J, Lampi AM. Plant sterols: biosynthesis, biological function and their importance to human nutrition. J Sci Food Agric. 2000;80:939-966.

11. Mandl A, Reich G, Lindner W. Detection of adulteration of pumpkin seed oil by analysis of content and composition of specific $\Delta$ 7-phytosterols. Eur Food Res Technol. 1999;209:400-406; https://doi.org/10.1007/s002170050516

12. Eller FJ, Moser JK, Kenar JA, Taylor SL. Extraction and analysis of tomato seed oil. J Am Oil Chem Soc. 2010;87:755-62. https:// doi.org/10.1007/s11746-010-1563-4.

13. Azadmard-Damirchi S, Dutta PC. Novel solid-phase extraction method to separate 4-desmethyl-, 4-monomethyl-, and 4,4'-dimethylsterols in vegetable oils. J Chromatogr A. 2006;1108:183-7. https://doi.org/10.1016/j.chroma.2006.01.015.

14. Azadmard-Damirchi S, Nemati M, Hesari J, Ansarin M, Fathi-Achachlouei B. Rapid separating and enrichment of 4,4'-dimethylsterols of vegetable oils by solid-phase extraction. J Am Oil Chem Soc. 2010;87:1155-9. https://doi.org/10.1007/ s11746-010-1595-9.

15. Kornfeldt A, Croon LB. 4-demethyl-, 4-monomethyl- and 4,4-dimethylsterols in some vegetable oils. Lipids. 1981;16:30614. https://doi.org/10.1007/BF02534954.

16. Fiebig HJ, Brühl L, Aitzetmüller K. Sterine - Isolierung und gaschromatographische Untersuchung. Lipid/Fett. 1998;100:422-428. 
17. Domeño C, Ruiz B, Nerín C. Determination of sterols in biological samples by SPME with on-fiber derivatization and GC/FID. Anal Bioanal Chem. 2005;381:1576-83. https://doi.org/10.1007/ s00216-005-3056-0.

18. Hammann S, Englert M, Müller M, Vetter W. Accelerated separation of GC-amenable lipid classes in plant oils by countercurrent chromatography in the co-current mode. Anal Bioanal Chem. 2015; https://doi.org/10.1007/s00216-015-9068-5

19. Battistel D, Piazza R, Argiriadis E, Marchiori E, Radaelli M, Barbante C. GC-MS method for determining faecal sterols as biomarkers of human and pastoral animal presence in freshwater sediments. Anal Bioanal Chem. 2015. https://doi.org/10.1007/ s00216-015-8998-2

20. Kovats E. Gas-chromatographische Charakterisierung organischer Verbindungen Teil 1: Retentionsindices aliphatischer Halogenide, Alkohole, Aldehyde und Ketone. Helv Chim Acta. 1958;41:191532. https://doi.org/10.1002/hlca.19580410703.

21. van den Dool H, Kratz PD. A generalization of the retention index system including linear temperature programmed gas-liquid partition chromatography. J Chromatogr A. 1963;11:463-71. https:// doi.org/10.1016/S0021-9673(01)80947-X.

22. Hammann S, Tillmann U, Schröder M, Vetter W. Profiling the fatty acids from a strain of the microalgae Alexandrium tamarense by means of high-speed counter-current chromatography and gas chromatography coupled with mass spectrometry. J Chromatogr A. 2013;1312:93-103. https://doi.org/10.1016/j.chroma.2013.08.090.

23. Vetter W, Walther W. Preparation of pyrrolidides from fatty acids via trimethylsilyl esters for gas chromatographic-mass spectrometric analysis. J Chromatogr A. 1990;513:405-7. https://doi.org/10. 1016/S0021-9673(01)89466-8.

24. Blumberg LM, Klee MS. Method translation and retention time locking in partition GC. Anal Chem. 1998;70:3828-9. https://doi. org/10.1021/ac971141v

25. Hammann S, Vetter W. Method development for the determination of free and esterified sterols in button mushrooms (Agaricus bisporus). J Agric Food Chem. 2016;64:3437-44. https://doi.org/ 10.1021/acs.jafc.6b00383.

26. Sommer K, Vetter W. Gas chromatography with mass spectrometry detection and characterization of 27 sterols in two truffle (Tuber) species. J Food Compos Anal. 2020;94:103650. https:// doi.org/10.1016/j.jfca.2020.103650.

27. Alencar JW, Craveiro AA, Matos FA. Kovats' indices as a preselection routine in mass spectra library searches of volatiles. J Nat Prod. 1984. https://doi.org/10.1021/np50035a028

28. Andersson $\mathrm{B} \AA$. Mass spectrometry of fatty acid pyrrolidides. Prog Chem Fats Other Lipids. 1978;16:279-308. https://doi.org/ 10.1016/0079-6832(78)90048-4.

29. Hauler C, Vetter W. A non-targeted gas chromatography/electron capture negative ionization mass spectrometry selected ion monitoring screening method for polyhalogenated compounds in environmental samples. Rapid Commun Mass Spectrom. 2015;29:619-28. https://doi.org/10.1002/rcm.7143.

30. Vetter W, Gallistl C, Schlienz A, Preston T, Müller J, von der Trenck K. Brominated flame retardants (BFRs) in eggs from birds of prey from Southern Germany, 2014. Environ Pollut. 2017;231:569-77. https://doi.org/10.1016/j.envpol.2017.08.047.

31. Goad J, Akihisa T. Analysis of sterols. Blackie Academic \& Professional. London, UK; 1997.
32. Karliner J, Djerassi C. Terpenoids LVII. Mass spectral and nuclear magnetic resonance studies of pentacyclic triterpene hydrocarbons. J Org Chem. 1966;31:1945-1956. https://doi.org/10.1021/ jo01344a063

33. Budzikiewicz H, Wilson JM, Djerassi C. Mass spectrometry in structural and stereochemical problems. XXXII. Pentacyclic triterpenes. J Am Chem Soc. 1963;85:3688-99. https://doi.org/10. 1021/ja00905a036.

34. Patterson GW. Relation between structure and retention time of sterols in gas chromatography. Anal Chem. 1971;43:1165-70. https://doi.org/10.1021/ac60304a015.

35. Ghosh A, Misra S, Dutta AK, Choudhury A. Pentacyclic triterpenoids and sterols from seven species of mangrove. Phytochemistry. 1985;24:1725-7. https://doi.org/10.1016/S0031-9422(00) 82541-8.

36. Schwartz H, Ollilainen V, Piironen V, Lampi A-M. Tocopherol, tocotrienol and plant sterol contents of vegetable oils and industrial fats. J Food Compos Anal. 2008;21:152-61. https://doi.org/ 10.1016/j.jfca.2007.07.012.

37. Reina RJ, White KD, Firestone D. Sterol and triterpene diol contents of vegetable oils by high-resolution capillary gas chromatography. J AOAC Int. 1999;82:929-35. https://doi.org/10.1093/ jaoac/82.4.929.

38. La Montserrat-de Paz S, Marín-Aguilar F, García-Gimenez MD, Fernández-Arche MA. Hemp (Cannabis sativa L.) seed oil: analytical and phytochemical characterization of the unsaponifiable fraction. J Agric Food Chem. 2014;62:1105-10. https://doi.org/ 10.1021/jf404278q.

39. Homberg E, Bielefeld B. Sterinzusammensetzung und Steringehalt in 41 verschiedenen pflanzlichen und tierischen Fetten. Lipid/ Fett. 1989;91:23-7. https://doi.org/10.1002/lipi.19890910106.

40. Homberg E, Bielefeld B. Hauptkomponenten der 4-Methylsterinund Triterpenfraktion von 12 Pflanzenfetten und ihr Einfluß auf die Sterinanalyse. Lipid/Fett. 1990;92:478-80. https://doi.org/10. 1002/lipi.19900921206.

41. Itoh T, Tamura T, Matsumoto T. Sterol composition of 19 vegetable oils. J Am Oil Chem Soc. 1973;50:122-5. https://doi.org/10. 1007/BF02633564.

42. Itoh T, Tamura T, Matsumoto T. Methylsterol compositions of 19 vegetable oils. J Am Oil Chem Soc. 1973;50:300-3. https://doi. org/10.1007/BF02641360.

43. Jeong TM, Itoh T, Tamura T, Matsumoto T. Analysis of methylsterol fractions from twenty vegetable oils. Lipids. 1975;10:634 40. https://doi.org/10.1007/BF02532729.

44. Jeong TM, Itoh T, Tamura T, Matsumoto T. Analysis of sterol fractions from twenty vegetable oils. Lipids. 1974;9:921-7. https://doi.org/10.1007/BF02532620.

45. Dutta PC, Normen L. Capillary column gas-liquid chromatographic separation of $\Delta 5$-unsaturated and saturated phytosterols. J Chromatogr A. 1998;816:177-84. https://doi.org/10.1016/S00219673(98)00520-2.

46. Di Vincenzo D, Maranz S, Serraiocco A, Vito R, Wiesman Z, Bianchi G. Regional variation in shea butter lipid and triterpene composition in four African countries. J Agric Food Chem. 2005;53:7473-9. https://doi.org/10.1021/jf0509759.

Publisher's note Springer Nature remains neutral with regard to jurisdictional claims in published maps and institutional affiliations. 